\title{
Investigation on the effect of mechanical vibration in mild steel weld pool
}

\author{
Pravin Kumar Singh \\ Department of Mechanical and Automation Engineering, AMITY University, Ranchi, India
}

Received: 17 May 2019 / Accepted: 27 July 2019

\begin{abstract}
This study presents a new concept of a vibratory welding setup which can transfer the mechanical vibrations in the weld zone during Shielded Metal Arc welding (SMAW) process and can also produce the resonance frequency of $300 \mathrm{~Hz}$. In the present investigation mild steel plates of $6 \mathrm{~mm}$ thickness has been butt welded using both conventional and vibratory welding conditions. Microstructure and the mechanical properties of the butt welded joints were evaluated, and the results were compared. Further, in order to optimize the process parameters of vibratory welding technique Taguchi and analysis of variance (ANOVA) technique have been adopted. The responses considered for analysis are hardness, ultimate tensile strength (UTS) and impact strength. The result of the study indicates that by applying the vibratory treatment during welding process the mechanical properties such as hardness, tensile strength and impact strength have been enhanced. Lastly, the obtained results are correlated from the results in the past researches.
\end{abstract}

Keywords: Vibratory welding / SMAW / Taguchi analysis / ANOVA / S/N ratio / tensile strength / hardness

\section{Introduction}

Welding is a homogeneous bond between two or more pieces of metal, where the strength of the welded joint exceeds the strength of the base pieces of metal. Some of the most common arc welding processes are: FCAW (Flux Cored Arc Welding), SMAW (Shielded Metal Arc Welding), SAW (Submerged Arc Welding), PAW (Plasma Arc Welding), GMAW (Gas Metal Arc Welding), GTAW (Gas Tungsten Arc Welding), etc. The microstructure of a welded joint is of great importance, since the mechanical properties are depended upon it [1]. Therefore, there is an urgent need to improve the mechanical properties of welded joints.

In present study, mechanical properties of the welded joints have been improved by refining its microstructure using vibratory welding process. Vibratory welding technique is the process of transferring the vibrations into the molten weld pool through various modes of vibratory setup. Various researches have performed on the vibratory welding techniques to improve the microstructure and mechanical properties of the weld joints [2]. In arc welding, vibration can be applied either during or after the process. The post weld vibration technique is referred to as Vibratory Stress Relief (VSR) technique; it is a stress relieving method. Continuing the search for higher

\footnotetext{
* e-mail: pravinsingh.phd@gmail.com
}

productivity, researchers are now putting their effort to develop the process of arc welding during vibration, i.e. vibration assisted welding (VAW), which can cut most of the expenses related to post-weld vibrations or heat treatments. Production lead time can be considerably reduced due to the parallel processing of vibration and welding [3]. Moreover, VAW leads to improved microstructure and better mechanical properties. Fine-grainstructures, associated with superior mechanical property, are the ultimate goal of a solidification process. It is widely accepted that the grain refinement is caused by dendrite fragmentation. Studies carried out by researchers in the past also proved that mechanical properties of any welded joints are mainly determined by its grain structure and the mode of solidification [4-7]. In the similar context, in the present study it has been proved that in comparison with the coarse grain structures, the fine structures have high strength and lesser chances of hot cracking. Many researchers have conducted studies to improve the vibratory setup and studied their effect on welding structures $[8,9]$. Therefore, a short description about the vibratory techniques used by various researchers to improve the various welding process has been discussed in Table 1. In recent years, High-frequency mechanical impact (HFMI) is used as one of the most recent finishing techniques to improve the fatigue resistance [10]. The effect of magnetic field and the ultrasound effect on solidification behavior have also been investigated by some authors [11-15]. 
Table 1. A comparative study between various vibratory welding techniques and the experimental setup used in the present work.

\begin{tabular}{|c|c|c|c|c|c|c|c|}
\hline S. No & $\begin{array}{l}\text { Material } \\
\text { used }\end{array}$ & $\begin{array}{l}\text { Vibratory } \\
\text { table }\end{array}$ & $\begin{array}{l}\text { Electromagnetic/ } \\
\text { ultrasonic/ultrasound } \\
\text { vibratory treatment, etc. }\end{array}$ & $\begin{array}{l}\text { Post weld } \\
\text { vibratory } \\
\text { treatment }\end{array}$ & $\begin{array}{l}\text { Frequency } \\
\text { produced }\end{array}$ & Process & Reference \\
\hline 1 & A-105 & $\sqrt{ }$ & & & $54-59 \mathrm{rps}$ & SAW & {$[3]$} \\
\hline 2 & AISI 310 & & Electromagnetic & & $0-40 \mathrm{~Hz}$ & GTAW & {$[6]$} \\
\hline 3 & $\begin{array}{l}\text { Al Alloy } \\
(1085,2214)\end{array}$ & & Electromagnetic & & $50 \mathrm{~Hz}$ & $\begin{array}{l}\text { Casting } \\
\text { process }\end{array}$ & [7] \\
\hline 4 & Nickel Alloy (690) & $\sqrt{ }$ & & & $58 \mathrm{~Hz}$ & GTAW & {$[8]$} \\
\hline 5 & MS & $\sqrt{ }$ & & $\sqrt{ }$ & $25 \mathrm{~Hz}$ & MIG & {$[9]$} \\
\hline 6 & D6AC, D406A & $\sqrt{ }$ & & $\sqrt{ }$ & $2.5 \mathrm{~Hz}$ & MIG & [10] \\
\hline 7 & A-105 & $\sqrt{ }$ & & & $54-59 \mathrm{rps}$ & SAW & {$[12]$} \\
\hline 8 & AL-6XN & & Ultrasonic & & $20 \mathrm{kHz}$ & SMAW & [13] \\
\hline 9 & Niomol $490 \mathrm{~K}$ & $\sqrt{ }$ & & $\sqrt{ }$ & - & SAW & [14] \\
\hline 10 & $\mathrm{SiC}_{\mathrm{p}} / 6061 \mathrm{Al}$ & & Ultrasound & & $50 \mathrm{kHz}$ & PAW & {$[15]$} \\
\hline 11 & Super alloy 800 & & Electromagnetic & & - & GTAW & [16] \\
\hline 12 & Al alloy & $\sqrt{ }$ & & & $100-3000 \mathrm{~Hz}$ & GTAW & {$[17]$} \\
\hline 13 & MS & $\sqrt{ }$ & & & - & SMAW & {$[18]$} \\
\hline 14 & $\mathrm{Al}$ alloy & & Wave guide & & $20 \mathrm{kHz}$ & MIG \&TIG & [19] \\
\hline 15 & 304-SS & $\sqrt{ }$ & & & $375 \mathrm{~Hz}$ & GTAW & {$[20]$} \\
\hline 16 & 304-SS & $\sqrt{ }$ & & & $150-350 \mathrm{~Hz}$ & TIG & {$[21]$} \\
\hline 17 & AISI 304 & & Horn plus tool & & $429 \mathrm{~Hz}$ & FSW & {$[22]$} \\
\hline 18 & AISI 304 & $\sqrt{ }$ & & & $60.9 \mathrm{~Hz}$ & TIG & [23] \\
\hline 19 & AZ31 Mg alloy & $\sqrt{ }$ & & & $15 \mathrm{kHz}$ & TIG & [24] \\
\hline 20 & Al Aluminum & & Pulsed MIG & & - & MIG & {$[25]$} \\
\hline 21 & Ferrite alloy & & $\begin{array}{l}\text { Ultrasonic } \\
\text { vibration }\end{array}$ & & $20 \mathrm{kHz}$ & $\begin{array}{l}\text { Under } \\
\text { water } \\
\text { welding }\end{array}$ & {$[26]$} \\
\hline 22 & $16 \mathrm{Mn}$ & & $\begin{array}{l}\text { Arc vibratory } \\
\text { welding }\end{array}$ & & $0.9 \mathrm{~g}$ & $\begin{array}{l}\mathrm{CO}_{2} \text { Arc } \\
\text { Welding }\end{array}$ & {$[27]$} \\
\hline 23 & AA6061-T6 & & Ultrasonic vibration & & $20 \mathrm{kHz}$ & FSW & {$[28]$} \\
\hline 24 & MS & $\sqrt{ }$ & & & $80-400 \mathrm{~Hz}$ & SMAW & [29] \\
\hline 25 & S690 Steel & & HFMI & & $40 \mathrm{kHz}$ & & [30] \\
\hline 26 & $M S$ & $\begin{array}{l}\text { A new con } \\
\text { which is ca } \\
\text { molten wel }\end{array}$ & $\begin{array}{l}\text { pt of vibratory setup has b } \\
\text { able to transfer the vibratio } \\
\text { oool during welding operati }\end{array}$ & $\begin{array}{l}n \text { designed } \\
\text { s in the }\end{array}$ & $80-300 \mathrm{~Hz}$ & $S M A W$ & $P W^{*}$ \\
\hline
\end{tabular}

Note: SMAW - shielded metal arc welding; MIG - metal inert gas; GTAW - gas tungsten arc welding; SAW - submerged arc welding; TIG - tungsten inert gas; HFMI - high frequency mechanical impact; PAW - plasma arc welding; PW*: - present work.

From the above discussed literature review, it can be concluded that no work exists on the use of induced auxiliary mechanical vibrations in the weld pool when it is in the molten state. Researchers have selected vibrating as a choice for the base metal or filler metal, nevertheless no area has declared publicly on inducing the auxiliary mechanical vibrations in the molten weld zone during welding operation.

In the present experimental work, the arrangement has been designed in such a manner that the specimen is fixed on the work-table and the vibratory set-up transfers the vibrations only to the molten weld, consequently transferring maximum energy to the weld zone during welding process. This experimental set-up designed in this study is much economical in comparison to the application of electromagnetic, ultrasound and ultrasonic techniques during welding operation. Further, it has been observed that the optimization of vibratory welding process parameter has not been discussed in the literature. Hence in order to fill this gap, Taguchi method has been utilized to find out the optimum levels of process parameters of vibratory welding in the present investigation. The Taguchi method provides a systematic and efficient methodology for process of optimization [31-34].

Microstructure and mechanical properties of the welded joints are also dependent on the cooling rate of welding structures. Pravin et al. [35] carried out a study on investigation on the effect of vibration on cooling 


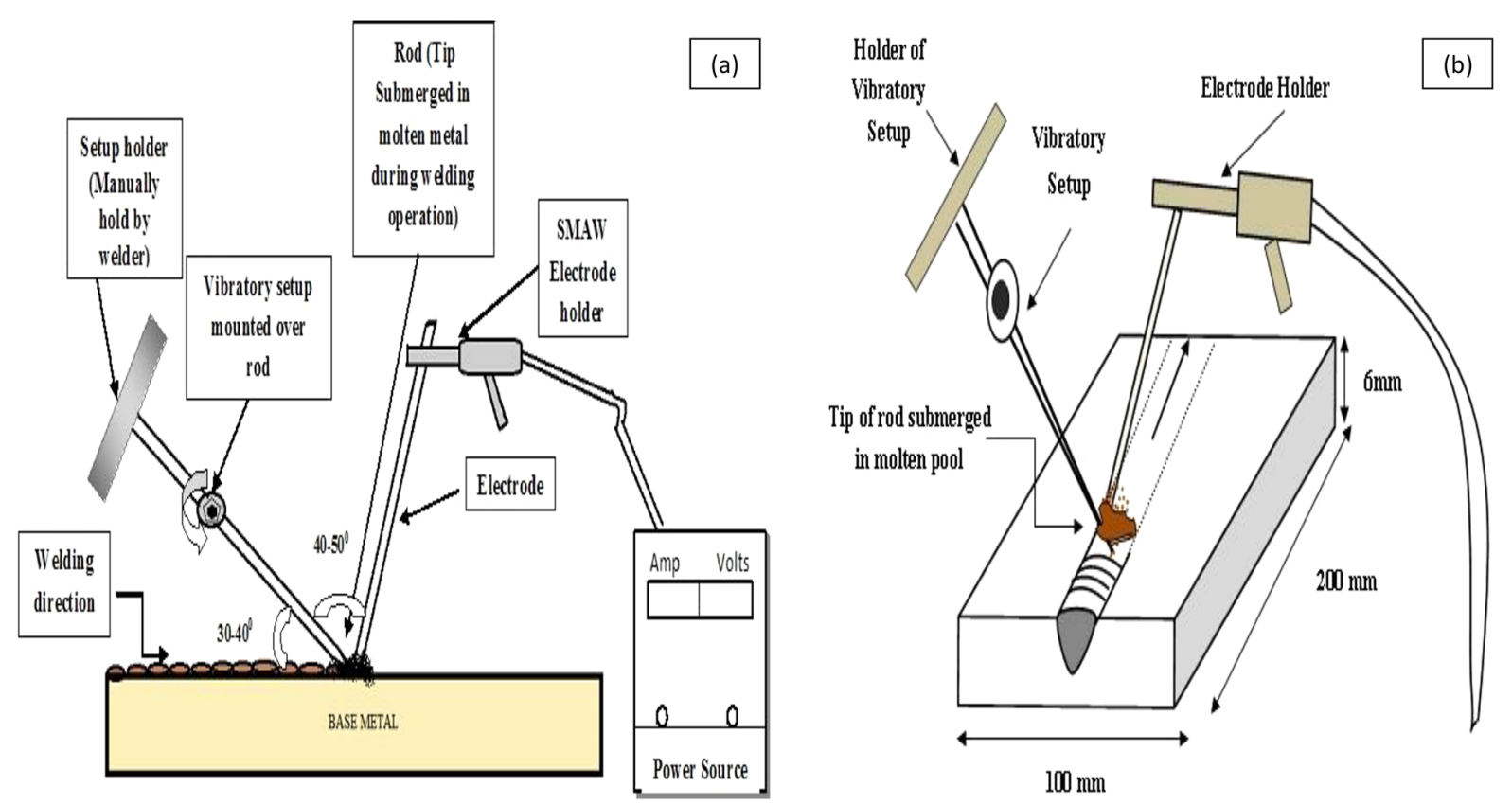

Fig. 1. (a) Schematic block diagram of vibratory setup presenting the angles and positions of vibratory setup. (b) Top view diagram of vibratory setup.

characterization of weld pool. The cooling curve shows that the application of vibration increases the thermal gradient during the welding operation. Comparatively faster cooling was found during the vibratory welding condition.

\section{Experimental procedure}

\subsection{Design of vibratory setup}

With the aim to improve the mechanical properties of the butt welded joint, a vibratory setup has been designed and developed in the present investigation, as shown in Figure 1. The primary function of the designed vibratory setup is that it is capable to stir the molten weld puddle before it solidifies. The tip of the rod of the vibratory setup is submerged into the molten weld zone, the vibration transfers through the non consumable rod into the molten weld zone and shakes the molten weld metal before it solidifies. In present experimentation, the vibratory welding process maintains the quasi-stationary state where the observer finds that at any instant of time across the entire weld length, the vibratory tip is submerged in the weld pool and transfers the vibrations in molten metal before it solidifies. The vibratory setup constantly moves in the same direction with the same speed as that of welding speed maintained by the welder. The approximate value of angles between the rod and the work piece and other measured angles are shown in Figure 1. The actual figure of vibratory setup and vibratory welding process is presented in Figure $2 \mathrm{a}-\mathrm{d}$. The vibrating rod is made of Thorium- Zirconium-Tungsten alloy, which makes it sustain at a very high temperature. The diameter of the rod is $3 \mathrm{~mm}$ and having a conical shape at one end side of the rod. The other end of the rod is attached with a non- conducting holder, used to grip the vibratory setup during the welding operation.
The eccentric rotation mass motor (ERM) is used to generate the vibration during the welding process. ERM motor is attached to the middle of the ThoriumZirconium-Tungsten rod. It is the most important device of the vibratory setup and works on the principle of rotation of unbalanced mass. ERM motor is standard DC motor with an off centre load attached to the shaft. In present investigation, two ERM motors were used. The specifications of the motors are presented in Table 2. To prevent the ERM motor from high heat during welding operation, ceramic pipes and piece of glasses were covered around ERM motor. Since the size of the motor is small, so the generated amplitude is relatively less. With an accelerometer, data acquisition and signal analysis the frequency of this vibratory setup has been determined. To prevent the vibratory setup from high heat during welding operation, the ERM motor is covered around with the ceramic pipes and piece of glasses.

\subsection{Preparation of specimens}

Shielded metal arc welding (SMAW) operation has been used for butt joint of Mild steel plates of size $200 \times 100 \times$ $6 \mathrm{~mm}$. The filler metal (E-3106) has been used as an electrode for SMAW process. The base metal used in the present experimentation was mild steel, composed of $0.16-$ $0.18 \%$ carbon, $0.40 \%$ silicon, $0.7-0.9 \%$ manganese, $0.04 \%$ phosphorus and $0.04 \%$ sulphur. In present investigation to avoid any defect all the constraints like, neat and clean rust free specimen, the flux coated electrode was free from any type of moisture, a proper weld structure was maintained, welding fixtures were used on the back side of the plates to avoid distortion etc. were considered. In the mean while stirring of the weld pool helps to release of the dissolve gases from the molten metal resulting, weld bead was free from 

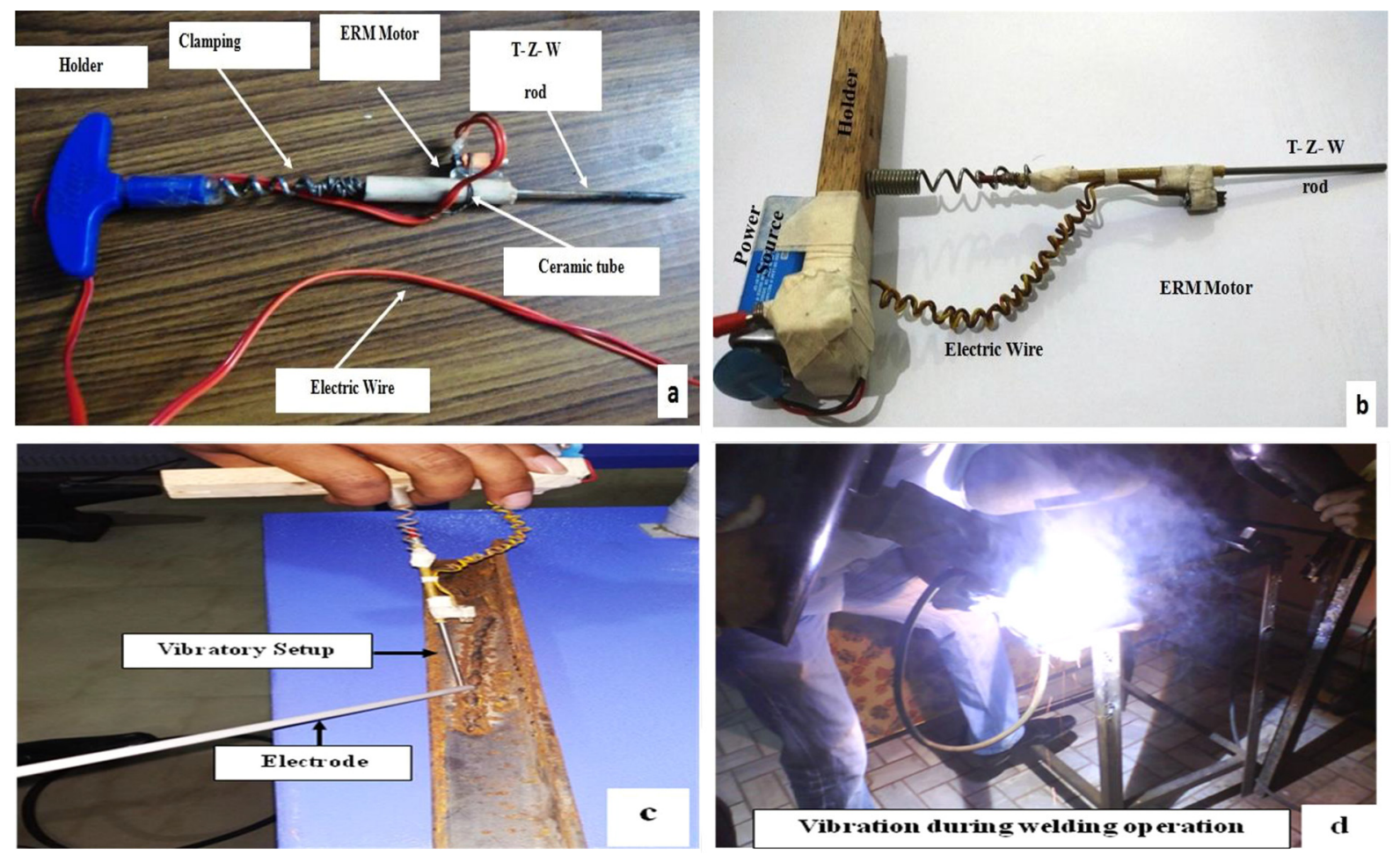

Fig. 2. (a) and (b) Photograph of actual vibratory setup. (c) and (d) Vibratory welding process used in present investigation.

Table 2. Specification of the ERM motor.

\begin{tabular}{lll}
\hline Specification & Micro motor & Coin motor \\
\hline Image of ERM motor & & \\
& $6 \mathrm{~V}$ & \\
& $-20^{\circ} \mathrm{C}$ to $60^{\circ} \mathrm{C}$ & $9 \mathrm{~V}$ \\
Rated operating voltage & Arbitrary rotation & $-20^{\circ} \mathrm{C}$ to $60^{\circ} \mathrm{C}$ \\
Operating environment & $9000 \pm 1000 \mathrm{RPM}$ & Arbitrary rotation \\
Direction of rotation & $150 \mathrm{~Hz}$ & $17,500 \pm 2500 \mathrm{RPM}$ \\
Rotor speed & & $300 \mathrm{~Hz}$ \\
Rated frequency & &
\end{tabular}

porosity defect. As a result of the precautions taken during welding operation the weld structure was uniform and defect free.

A set of experimental work has been designed by Taguchi method. The required responses are dependent upon the arrangement of the input parameters during each experiment. These types of metrics are called an orthogonal array. The values of the process parameters at different levels are mentioned in Table 3, such parameters were selected which makes more effects on the desired output. The experiments were arranged in three levels of frequencies $[300 \mathrm{~Hz}, 150 \mathrm{~Hz}$ and $0 \mathrm{~Hz}$ (conventional condition)], three levels of current (60,80 and $100 \mathrm{amp})$ and three levels of speed $(6,8$ and $10 \mathrm{~cm} / \mathrm{min})$. The suitable orthogonal array describes the experiment plan on the basis of degrees of freedom.

In this experiment Signal-to-Noise ratio has been used to examine the effect of each factor on a particular response. The signals show the effect of each factor on the response, whereas noise is the measure of the influence on the deviation from the average responses. $\mathrm{S} / \mathrm{N}$ ratio is based upon the lower-the-better, larger- the- better and 
Table 3. Input parameters and levels.

\begin{tabular}{lllll}
\hline Variables & Unit & \multicolumn{3}{c}{ Levels } \\
\cline { 3 - 5 } & & 1 & 2 & 3 \\
\hline Current $(I)$ & Amp & 60 & 80 & 100 \\
Welding speed $(S)$ & $\mathrm{cm} / \mathrm{min}$ & 10 & 15 & 20 \\
Frequency $(f)$ & $\mathrm{Hz}$ & 0 & 150 & 300 \\
\hline
\end{tabular}

Table 4. Results obtained from hardness, impact and tensile tests for $\mathrm{L}_{9} \mathrm{OA}$.

\begin{tabular}{|c|c|c|c|c|c|c|c|c|c|}
\hline \multirow[t]{2}{*}{ Test no. } & \multicolumn{3}{|c|}{ Coded values } & \multicolumn{3}{|c|}{ Actual settings } & \multicolumn{3}{|c|}{ Response value } \\
\hline & $I$ & $S$ & $F$ & $C(\mathrm{AMP})$ & $S(\mathrm{~cm} / \mathrm{min})$ & $f(\mathrm{~Hz})$ & $H(\mathrm{VHN})$ & $J$ (Joule) & UTS (MPa) \\
\hline 1 & 1 & 1 & 1 & 60 & 10 & 0 & 250.00 & 56 & 543.94 \\
\hline 2 & 1 & 2 & 2 & 60 & 15 & 150 & 275.00 & 62 & 572.54 \\
\hline 3 & 1 & 3 & 3 & 60 & 20 & 300 & 299.00 & 49 & 597.91 \\
\hline 4 & 2 & 1 & 2 & 80 & 10 & 150 & 271.00 & 63 & 572.00 \\
\hline 5 & 2 & 2 & 3 & 80 & 15 & 300 & 292.32 & 48 & 609.00 \\
\hline 6 & 2 & 3 & 1 & 80 & 20 & 0 & 260.00 & 58 & 545.86 \\
\hline 7 & 3 & 1 & 3 & 100 & 10 & 300 & 289.90 & 51 & 600.33 \\
\hline 8 & 3 & 2 & 1 & 100 & 15 & 0 & 255.00 & 54 & 550.72 \\
\hline 9 & 3 & 3 & 2 & 100 & 20 & 150 & 279.00 & 60 & 580.36 \\
\hline
\end{tabular}

nominal-the better criteria. The $\mathrm{S} / \mathrm{N}$ ratio is based on the previous knowledge and expertise, so it must be carefully chosen [32,33]. In this study responses are associated with the strength of the weld joint, which should be high as possible so the larger-the- better criteria has been chosen. The strength of the weld joint which is generally expected to be high is examined by equation (1)

$$
\frac{S}{N}=-10 \log _{10}\left(\frac{1}{n} \sum_{i=0}^{n} 1 / y_{i}^{2}\right)
$$

where $n=$ number of measurements; $y_{i}=$ response value for each noise factor; $i=$ number of design parameters in this study OA has 9 experiments (L9).

The Orthogonal array is designed by 9 numbers of experiments, so its total Degree of freedom will be $9-1=8$. To study the influence of each parameter to the response value, Analysis of Variance (ANOVA) technique has been used. ANOVA states that total sum of squares of the deviation are equal to the sum of square of standard deviation caused by each input factor [34].

\subsection{Metallurgical study of specimen}

In order to study the effect of auxiliary vibrations induced in the weld zone and its consequentially effect on the corresponding microstructure, the metallographic studies were conducted on different weld samples. These surfaces are electrolytically etched using the following conditions: Electrolyte used: Oxalic acid $(10 \mathrm{~g})+$ Distilled water $(100 \mathrm{ml})$, cell voltage $-6 \mathrm{~V}$, etching time $-1 \mathrm{~min}$.

\subsection{Mechanical testing}

The butt-welded specimen has been initially dimensioned and cut in such a way that the sample for impact test, tensile test and microstructure study could be taken. The tensile specimens were prepared in accordance with ASTM E-08 standards. Tensile specimens were tested on a Universal testing machine, (Make: FIE, Capacity: $600 \mathrm{kN}$ ). The displacement rate was $0.5 \mathrm{~mm} / \mathrm{min}$ [36]. The Charpy $\mathrm{V}$ - Notch Impact testing was conducted at the room temperature. According to ASTM E-23, three specimens having dimension of $(6 \mathrm{~mm} \times 10 \mathrm{~mm} \times 55 \mathrm{~mm})$ with $45^{\circ}$ notch of $2 \mathrm{~mm}$ depth and $0.25 \mathrm{~mm}$ radius were prepared. The test was carried out on the Instrumented Charpy machine, Zwick-Rowell make having $450 \mathrm{~J}$ capacity. Microhardness tester (Make: Omnitech, Capacity: 1000 grams) was used to measure microhardness at various zones of interest in different weldments. A load of 500 grams and a dwell time of 20 seconds were used for these studies. The hardness value was measured along the center line and the mid-thickness of the weld joint, each point was measured three times to inquire about its average value.

\section{Result and discussions}

The weld joints have been prepared at different level of frequencies $(f)$, welding current $(I)$ and welding speed $(S)$ and mechanically tested. From the various process parameters of welding, current and welding speed were selected, since these parameters are most basic and very effective for the mechanical properties of butt welded joints. 
Table 5. Response table for $\mathrm{S} / \mathrm{N}$ ratio of hardness of $\mathrm{L}_{9} \mathrm{OA}$.

\begin{tabular}{llll}
\hline Level & Current $(I)$ & Speed $(S)$ & Frequency $(f)$ \\
\hline 1 & 48.75 & 48.62 & 48.13 \\
2 & 48.76 & 48.74 & 48.79 \\
3 & 48.76 & 48.91 & 49.36 \\
Delta & 0.01 & 0.29 & 1.23 \\
Rank & 3 & 2 & 1 \\
\hline
\end{tabular}

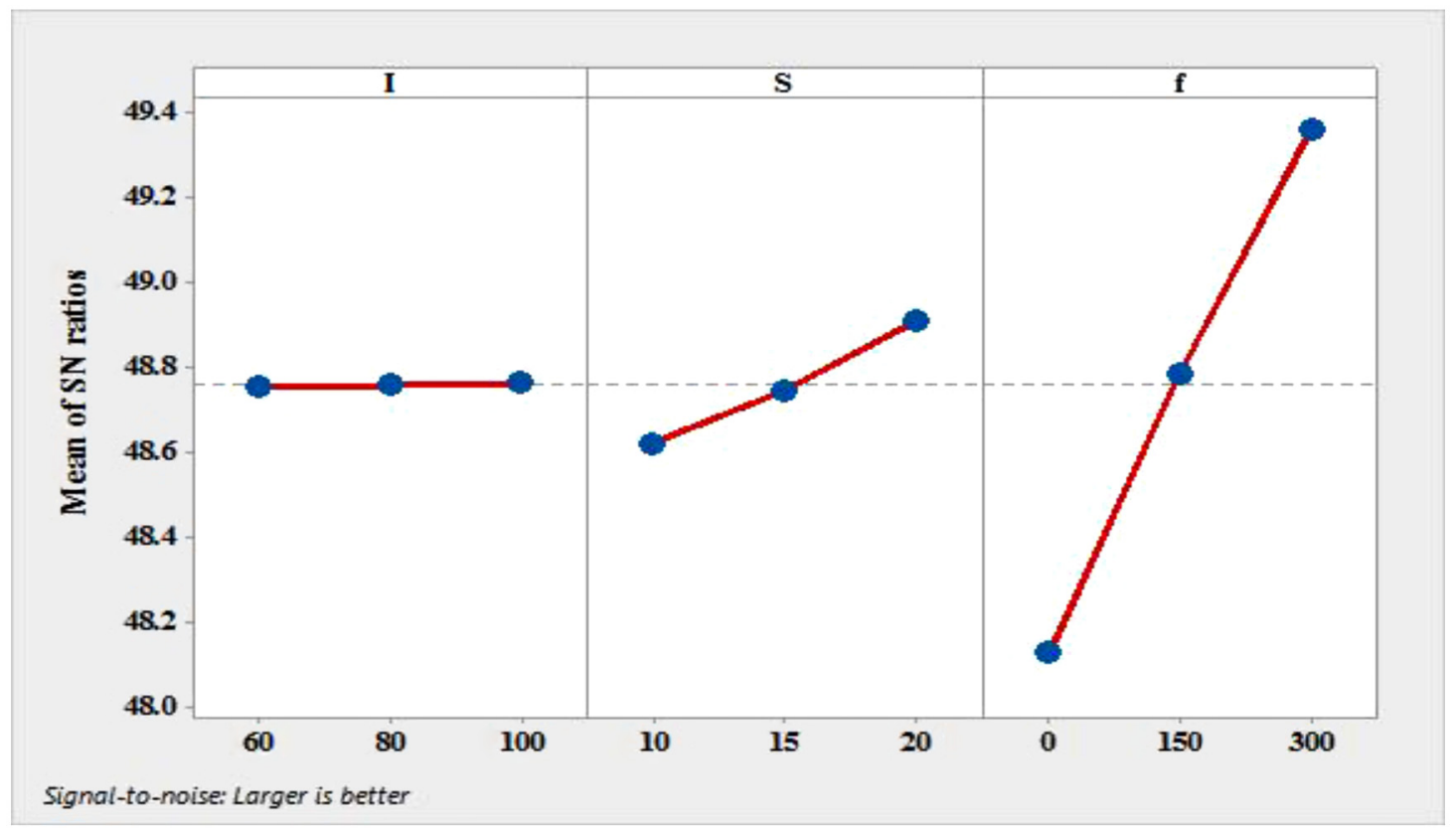

Fig. 3. Main effect plot of $\mathrm{S} / \mathrm{N}$ ratio of hardness values for $\mathrm{L}_{9} \mathrm{OA}$.

Ultimate tensile strength (UTS), micro-hardness $(H)$ and impact strength $(J)$ were chosen as response value. Table 4 describes the results obtained from the Tensile, Hardness and Impact tests at various welding conditions. The interaction effect between welding parameters is not considered. In second, third and fourth column the $\mathrm{L}_{9}$ orthogonal Array $(\mathrm{OA})$ is in coded form. The actual value for welding current $(I)$, welding speed $(S)$ and applied frequency $(f)$ is mentioned in column 5,6 and 7 respectively. The response values hardness $(H)$, impact strength $(J)$ and tensile strength (UTS) is mentioned in column 8,9 and 10 respectively. The design of experiment was prepared with the help of MINITAB 17.

\subsection{Micro-hardness analysis}

The response table and graph of the $\mathrm{S} / \mathrm{N}$ ratio for the hardness values are given in Table 5 and Figure 3 respectively. The optimal factors are obtained at the welding speed of $20 \mathrm{~cm} / \mathrm{min}$ (level 3), frequency at $300 \mathrm{~Hz}$ (level 3) and no influence of welding current has been found on the hardness value. From Figure 3 it is clear that by increasing frequency and welding speed the response value (hardness) increases whereas a straight line has been found for welding current which shows not much influence of welding current on response value. Table 6 shows the rank of the input parameters. Frequency has 1st rank, speed shows 2nd and current shows 3rd rank which indicate that the most influencing factor is frequency than welding speed and at last welding current. To validate the Taguchi's report, Analysis of Variance (ANOVA) technique has been applied and the percentage contribution $[34,37,38]$ of each process parameters on the hardness value is calculated with the help of equation (2).

$$
\begin{aligned}
& \text { Percentage Distribution for Hardness values }(\mathrm{PH}) \\
& \quad=\left(\mathrm{SS}_{\mathrm{d}}\right) /\left(\mathrm{SS}_{\mathrm{T}}\right)
\end{aligned}
$$

$\mathrm{SS}_{\mathrm{d}}=$ sum of the squared deviations; $\mathrm{SS}_{\mathrm{T}}=$ sum of the squared total.

Table 6 shows the analysis of variance (ANOVA) for one of the response value i.e. Hardness. The ANOVA results reported that frequency acts as a most significant factor having $94.5 \%$ contribution, followed by welding speed. The second affecting factor is welding speed. By increasing the welding speeds from 10 to $20 \mathrm{~cm} / \mathrm{min}$, the micro-hardness property of the welded joint improves. As theoretical knowledge says that at high welding speed least amount of heat is transferred to the weld zone causes the increase in the solidification rate of the weld zone which 
Table 6. Analysis of variance for hardness of $\mathrm{L}_{9} \mathrm{OA}$.

\begin{tabular}{lllllll}
\hline Source & DOF & Sum of squares $(\mathrm{SS})$ & Variance $(V)$ & $F$-ratio & $P$-value & $\% P_{\mathrm{H}}$ \\
\hline Current $(I)$ & 2 & 0.09 & 0.04 & 0.03 & 0.970 & $0 \%$ \\
Speed $(S)$ & 2 & 123.41 & 61.70 & 42.12 & 0.023 & $5.2 \%$ \\
Frequency $(f)$ & 2 & 2251.98 & 1125.99 & 768.63 & 0.001 & $94.5 \%$ \\
Error & 2 & 2.93 & & & & \\
Total & 8 & 2378.40 & $R$-Sq $(\mathrm{adj})=99.51 \%$ & & & \\
$R$-Sq $=99.88 \%$ & & & & & \\
\hline
\end{tabular}

Table 7. Response table for $\mathrm{S} / \mathrm{N}$ ratio of impact strength of $\mathrm{L}_{9} \mathrm{OA}$.

\begin{tabular}{llll}
\hline Level & Current $(I)$ & Speed $(S)$ & Frequency $(f)$ \\
\hline 1 & 34.87 & 35.03 & 34.96 \\
2 & 34.96 & 34.71 & 35.80 \\
3 & 34.79 & 34.88 & 33.86 \\
Delta & 0.17 & 0.33 & 1.94 \\
Rank & 3 & 2 & 1 \\
\hline
\end{tabular}

leads to the fine structures and high hardness values. Welding speed is the primary and non-electrical parameter which influences the heat input per unit length of the weld and consequently, it has influenced the micro-hardness of the welds in the present work.

The research of Balasubramanian and Balusamy [17] reported that the hardness of the weldment increases significantly with increasing in the frequency of vibration. From the main effect plot (refer Fig. 3), the result depicts the same condition as the frequency increases the hardness value enhanced simultaneously. Ye et al. [26] presented his research on electro-pulsing assisted ultrasonic impact treatment and concluded that the ultrasonic vibrations enhanced the micro-hardness of the weld joint. In the resent research article, Fouladi and Abbasi [39] discussed about the effect of vibration on friction stir welding and concluded that imposed vibration in friction stir welding increase the hardness of the weld specimen. In the present study, frequency is the main cause of the enhancement of the hardness value of the vibratory welded joints.

\subsection{Impact strength analysis of $L_{9} \mathrm{OA}$}

The $\mathrm{S} / \mathrm{N}$ ratio and main effect plot for impact strength is mentioned in Table 7 and Figure 4 respectively. The most favorable factors are found at welding current of $80 \mathrm{Amp}$ (level 2), welding speed of $10 \mathrm{~cm} / \mathrm{min}$ (level 1) and frequency at $150 \mathrm{~Hz}$ (level 2). Table 8 shows the analysis of variance (ANOVA) for the Impact strength. ANOVA table depicts that the most significant factor is frequency having $92 \%$ of the contribution (PI) on response value (Impact strength). As shown in Figure 4 (i.e. Main effect plot of $\mathrm{S} / \mathrm{N}$ ratio of Impact strength for $\mathrm{L}_{9} \mathrm{OA}$ ) the welded specimens has been improved up to the certain range of frequency $(150 \mathrm{~Hz})$, but when the frequency has been further increased up to its resonance value $(300 \mathrm{~Hz})$, the impact value decreases. Further results revealed the joints welded using low Welding current (80 Amp) showed higher
Impact energy absorption capacity than those welded using high Welding Current (100 Amp), and higher Impact strength is found at lowest welding speed $(10 \mathrm{~cm} / \mathrm{min})$. In this case frequency is the most influencing factor at $150 \mathrm{~Hz}$ (2nd level).

Previous research reported that the effect of vibration on impact property mechanics is complex $[2,3,14,18,40]$. $\mathrm{Lu}[3]$ and Pucko [14] studied the effect of vibration on the Impact strength and found the uneven changes in the impact properties of the vibratory weld-pool. Jose et al. [2] says that vibratory treatment has not any significant affect on the impact strength. Rao et al. [18] reported that the impact strength of the weld joint has been improved by the application of vibration during welding upto certain range of applied vibrations. So, on the basis of the above literature and results obtained from the present investigation, it has been observed that further research is needed to understand more about this phenomenon.

\subsection{Tensile strength of $L_{9} O A$}

Analysis of the $\mathrm{S} / \mathrm{N}$ ratio for the tensile strength is shown in Table 9. The applied vibration enhanced the Ultimate tensile strength (UTS) of the butt welded joints drastically. Frequency has highest value of delta i.e. 0.84 and it has rank 1 which indicates that the most influencing factor for the tensile strength is frequency followed by welding current (rank 2) and welding speed (rank 3). S/N graph/ main effect plot for tensile strength is mentioned in Figure 5 . The significant factors for highest UTS value has been found at welding current of $100 \mathrm{Amp}$ (level 3), welding speed at $15 \mathrm{~cm} / \mathrm{min}$ (level 2) and the frequency at its resonant level that is $300 \mathrm{~Hz}$ (level 3). The ANOVA result shows (Tab. 10) that the most influencing factor is frequency, having $97 \%$ of the contribution $\left(P_{\mathrm{U}}\right)$ on the desired response. Further it has been observed that the specimens welded using low heat input (i.e. at low welding current $60 \mathrm{Amp}$ ) did not experience any such appreciable 


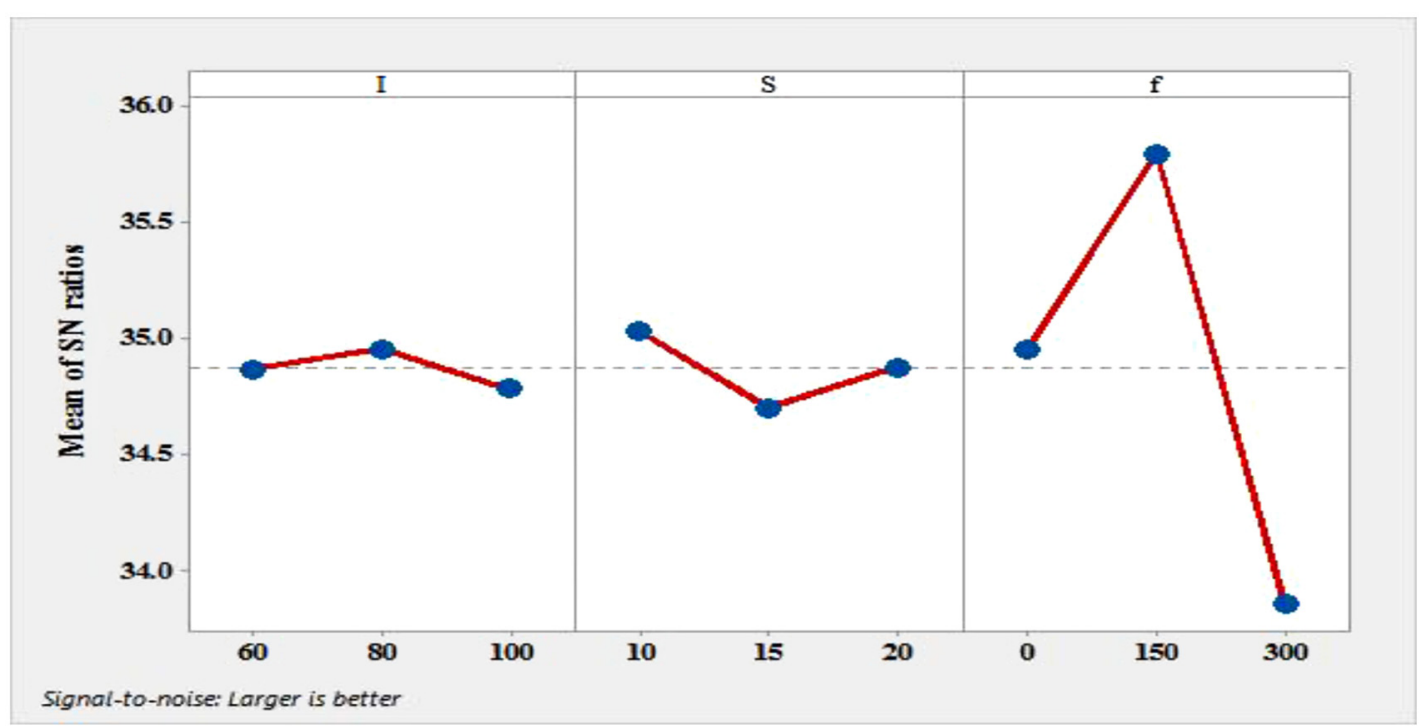

Fig. 4. Main effect plot of $\mathrm{S} / \mathrm{N}$ ratio of Impact strength for $\mathrm{L}_{9} \mathrm{OA}$.

Table 8. Analysis of variance for impact strength of $\mathrm{L}_{9} \mathrm{OA}$.

\begin{tabular}{lllllll}
\hline Source & DOF & Sum of squares $(\mathrm{SS})$ & Variance $(V)$ & $F$-ratio & $P$-value & $\% P_{I}$ \\
\hline Current & 2 & 2.67 & 1.33 & 0.31 & 0.765 & $1.08 \%$ \\
Speed & 2 & 6.00 & 3.00 & 0.69 & 0.591 & $2.43 \%$ \\
Frequency & 2 & 228.667 & 114.33 & 26.38 & 0.037 & $92 \%$ \\
Error & 2 & 8.67 & & & & \\
Total & 8 & 246.00 & $R$-Sq $(\mathrm{adj})=85.91 \%$ & & & \\
$R$-Sq $=96.48 \%$ & & & & & \\
\hline
\end{tabular}

Table 9. Response table for $\mathrm{S} / \mathrm{N}$ ratio of UTS of $\mathrm{L}_{9} \mathrm{OA}$.

\begin{tabular}{llll}
\hline Level & Current $(I)$ & Speed $(S)$ & Frequency $(f)$ \\
\hline 1 & 55.13 & 55.14 & 54.76 \\
2 & 55.19 & 55.22 & 55.19 \\
3 & 55.22 & 55.18 & 55.60 \\
Delta & 0.09 & 0.08 & 0.84 \\
Rank & 2 & 3 & 1 \\
\hline
\end{tabular}

changes, since the weld pool formed using low welding current was not influenced significantly by the vibratory condition. At high welding current the weld pool temperature is high due to which density of the weld metal is relatively lesser as compared to that of the weld pool metal formed at lower welding current. This density difference between the weld pools at different temperatures responded differently to the auxiliary vibrations, i.e. at low temperature weld metal was sluggish in responding to the vibrations induced in it.

Various researchers have shown their interest to study the effect of vibration on tensile properties of welded joints and found a positive response from their investigations. Mostafapour and Gholizadeh [21] reported that by increasing frequency from zero to resonance frequency the mechanical property improved. In the present study, the tensile property shows the same characteristic; the ultimate tensile strength is minimum at zero frequency and maximum at the resonance frequency level $(300 \mathrm{~Hz})$. Amini and Amiri [22] studied the effect of vibration on friction stir welding and found that tensile strength has been enhanced due to the application of vibration. Rahmi and Abbasi [27] modified a new version of friction stir welding (FSW) and referred as friction stir vibratory welding process. The strength of the vibratory welded joint was compared with joints prepared by the convention FSW and concluded that welded specimens with vibration are more strengthening than the conventional FSW. Following the previous 


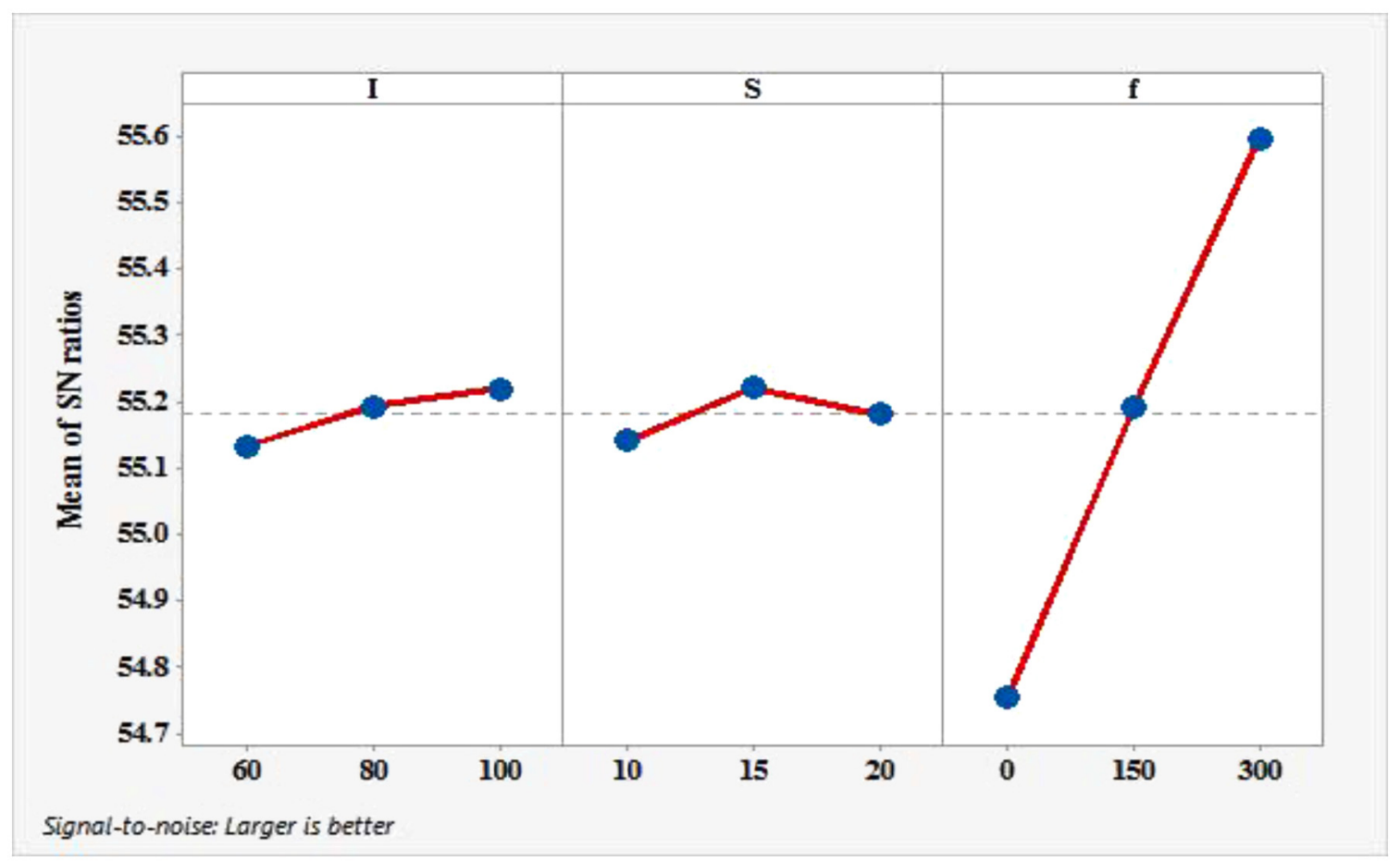

Fig. 5. Main effect plot of $\mathrm{S} / \mathrm{N}$ ratio of UTS for $\mathrm{L}_{9} \mathrm{OA}$.

Table 10. Analysis of variance for UTS of $\mathrm{L}_{9} \mathrm{OA}$.

\begin{tabular}{lllllll}
\hline Source & DOF & Sum of squares & Variance & $F$-ratio & $P$-value & $\% P_{\mathrm{U}}$ \\
\hline Current & 2 & 51.76 & 25.88 & 1.24 & 0.447 & $1.08 \%$ \\
Speed & 2 & 42.62 & 21.31 & 1.02 & 0.495 & $0.89 \%$ \\
Frequency & 2 & 4632.82 & 2316.41 & 110.77 & 0.009 & $97 \%$ \\
Error & 2 & 41.82 & & & & \\
Total & 8 & 4769.03 & & & & \\
$R$-Sq $=99.12 \%$ & & $R$-Sq $(\mathrm{adj})=96.49 \%$ & & & & \\
\hline
\end{tabular}

research it has been observed that the vibratory setup used in the present investigation is capable to enhance the mechanical properties of the weld joints.

To evaluate the joint efficiency of the vibratory welded specimen, further experiments were conducted at the best found optimum vibratory welding parameters. The joint efficiency [35] of the welded joints can be calculated by equation (3)

$$
\begin{aligned}
& \text { Joint efficiency of the weld structure } \\
& =\frac{\text { UTS(weld joint) }}{\text { UTS(base metal) }} .
\end{aligned}
$$

The calculated UTS value of base metal is $520 \mathrm{Mpa}$. The optimum welding parameters for maximum tensile strength are: current $=100 \mathrm{Amp}$, frequency $=300 \mathrm{~Hz}$ and speed $=15 \mathrm{~cm} / \mathrm{min}$.

The joint efficiency of vibratory welded joint is mentioned in Table 11.

\subsubsection{R-test}

Analysis of the effectiveness of the models for Hardness, Impact strength and Tensile strength responses performed by the help of $R^{2}$ (coefficient of determination, $R^{2}$ ) values. $R^{2}$ (Coefficient of determination) is used to check the goodness of the model; it determines how close the predicted values with the experimental values [36,41-44]. When $R^{2}$ approaches to the value of 1 , implying the response models have closely resembled the actual (experimental) data. It presents the good agreement exists between the predicted values and experimental values. The values of $R^{2}$ value for the hardness (Tab. 6) $R$-sq $=99.88 \%$ and $R$-sq $(\operatorname{adj})=99.51 \%$, for impact strength (Tab. 8) $R$-sq $=96.48 \%$ and $R$-sq $(\operatorname{adj})=85.91 \%$ and for tensile strength (Tab. 10) $R$-sq $=99.12 \%$ and $R$-sq (adj) $=96.49 \%$. These values indicate the goodness of designed model and proof that designed model is valid.

A brief conclusion of the results obtained in present experiment is presented in the Table 12 . 
Table 11. Joint efficiency of vibratory welded joints.

\begin{tabular}{llllll}
\hline $\begin{array}{l}\text { Experiment } \\
\text { No. }\end{array}$ & $\begin{array}{l}\text { Welding } \\
\text { current }\end{array}$ & $\begin{array}{l}\text { Welding } \\
\text { speed }\end{array}$ & $\begin{array}{l}\text { Frequency } \\
(\mathrm{Hz})\end{array}$ & $\begin{array}{l}\text { UTS } \\
(\mathrm{Mpa})\end{array}$ & $\begin{array}{l}\text { Joint efficiency } \\
(\%)\end{array}$ \\
\hline 1 & 60 & 10 & 0 & 543.94 & 104.60 \\
2 & 60 & 15 & 150 & 572.54 & 110.10 \\
3 & 60 & 20 & 300 & 597.91 & 114.9 \\
4 & 80 & 10 & 150 & 572.00 & 110 \\
5 & 80 & 15 & 300 & 609.00 & 117.1 \\
6 & 80 & 20 & 0 & 545.86 & 104.8 \\
7 & 100 & 10 & 300 & 600.33 & 115.44 \\
8 & 100 & 15 & 0 & 550.72 & 105.90 \\
9 & 100 & 20 & 150 & 580.36 & 111.60 \\
$10^{*}$ & 100 & 15 & 300 & 621.94 & 119.6 \\
\hline
\end{tabular}

Note: The $\left(^{*}\right)$ mark is showing the optimum input parameters and joint efficiency of vibratory welded joint.

Table 12. Concluded results from Taguchi's experiment and description of most significant value by ANOVA.

\begin{tabular}{lllll}
\hline $\begin{array}{l}\text { Responses/Input } \\
\text { parameters }\end{array}$ & $\begin{array}{l}\text { Current } \\
(\mathrm{Amp})\end{array}$ & $\begin{array}{l}\text { Welding speed } \\
(\mathrm{cm} / \mathrm{min})\end{array}$ & $\begin{array}{l}\text { Frequency } \\
(\mathrm{Hz})\end{array}$ & $\begin{array}{l}\text { ANOVA result (\% Contribution } \\
\text { of most significant factor) }\end{array}$ \\
\hline Hardness & 60 & 10 & $300^{*}$ & Frequency with $94.5 \%$ \\
Impact strength & 80 & 15 & $150^{*}$ & Frequency with $92 \%$ \\
UTS & 100 & 20 & $300^{*}$ & Frequency with $97 \%$ \\
\hline
\end{tabular}

Note: '*' mark showing the most significant factor for particular response.

\subsection{Microstructure characterization}

The metallographic properties of the weld joint prepared under the best optimal conditions $(I=100$ Amp, $S=15 \mathrm{~m} / \mathrm{sec}$ and $f=300 \mathrm{~Hz}$ ) has been investigated. One set of weld joint was prepared under the conventional condition i.e. without use of vibration during SMAW. A comparative study of the microstructures is being reported. The micrographs of different weldments and macro-sections/weld profiles cross- sections (for butt welded joints) are presented in Figure 6. Figure 6a and $\mathrm{b}$ shows the macro graph and microstructure of conventionally welded butt joint respectively. Figure $6 \mathrm{c}$ is the macrograph of vibratory welded butt joint prepared at $150 \mathrm{~Hz}$ of frequency. The corresponding microstructure is presented in Figure 6d. The macrograph of butt joint specimen prepared at $300 \mathrm{~Hz}$ of frequency is depicted in Figure $6 \mathrm{e}$ and its corresponding microstructure is presented in Figure 6f. The comparative study of the microstructures shows that welding under vibratory conditions (150 and $300 \mathrm{~Hz})$ has fine grain structures as compared to the conventional condition.

The imposed vibration during welding process produces following affects [25-27,39,45,46]:

- breaks the growing dendrites,

- increases the cooling rate,

- prevents the newborn nucleus from re-melting,
- increases the number of grains and

- produces the fine grain structure.

The microstructure characterization can be understand by the fact, that when the vibration imposed in the molten weld pool, it generates some disturbances during solidification $[28-30,37,40,47,48]$. The growing dendrite tip gets fragmented and is converted into the small size of dendrites. The fragmented dendrite serves as a new nucleation sties, if this tiny nucleus is sustained at a higher temperature then it will further grow up in the form of new grain.

Microstructure and mechanical properties of the welded joints are also dependent on the cooling rate of welding structures. Pravin et al. [38] carried out a study on investigation on the effect of vibration on cooling characterization of weld pool. The cooling curve shows that the application of vibration increases the thermal gradient during the welding operation. Comparatively faster cooling was found during the vibratory welding condition. The sustainability of the new born nucleus depends upon the super-cooling temperature of the solidifying structure, which provides the critical radius to the new born nucleus. The imposed vibration during welding stirs the molten metal before it solidifies, this interruption increases the cooling rate of the molten weld zone and helps to reach the super-cooling temperature. So, for the fine grain structure both the dendrite fragmentation and high cooling rate is important 

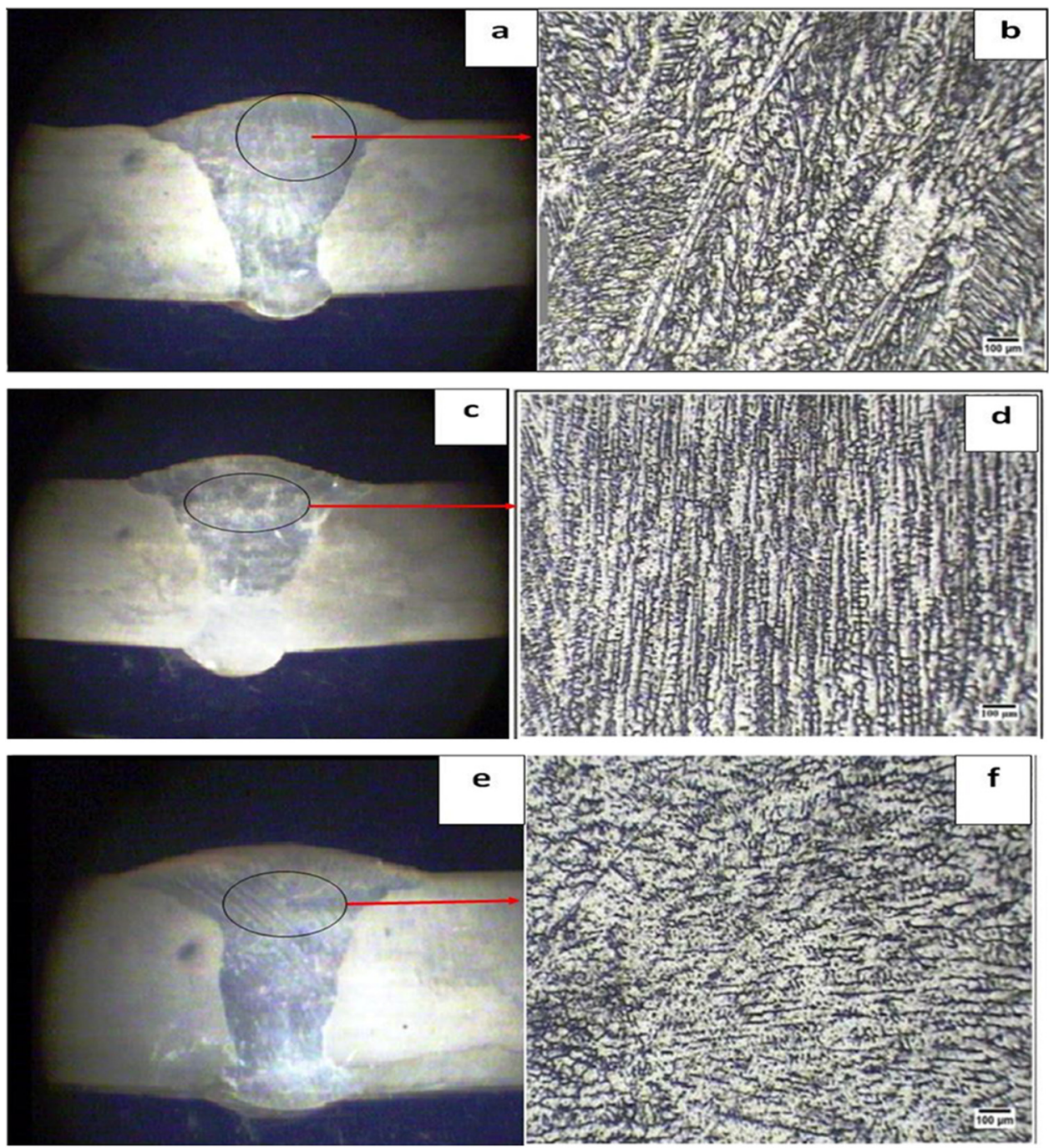

Fig. 6. (a) Macrograph of the conventional SMAW. (b) Microstructure analysis of conventional SMAW under no vibration condition. (c) Macrograph of the Vibratory SMAW. (d) Microstructure analysis of Vibratory SMAW under $150 \mathrm{~Hz}$ of frequency. (e) Macrograph of the Vibratory SMAW. (f) Microstructure analysis of Vibratory SMAW under $300 \mathrm{~Hz}$ of frequency. Stereo zoom (10 X) images showing the cross section of the weld profile and photomicrograph $(100 \mathrm{X})$ of Butt welded joint of the weld zone of the conventional and vibratory SMAW.

\section{Conclusions}

The development of a vibratory setup and the experimental investigations by employing the setup are concluded as follows:

- the work as presented here has shown and proved that it is possible to enhance the mechanical properties of welded joints if favorable mechanical vibrations are induced into the weld pool. Thus, the present research attempt provided an alternative for grain refinement of weldments. The efficiency of the vibratory setup developed and used in the present work was found to be satisfactory in terms of giving better weld properties.

- the important process parameters of vibratory welding technique namely welding current $(I)$, welding speed $(S)$ and frequency $(f)$ were optimized using Taguchi's analysis. The main effect plot shows that the hardness and tensile strength is principally affected by the frequency. It is evident from ANOVA results that frequency is the most influencing factor for changing the mechanical properties of welded joints.

- the impact property of weld joints shows uneven behavior, due to which the impact strength increases up to the $150 \mathrm{~Hz}$ of frequency and then decreases at the resonance frequency at $300 \mathrm{~Hz}$. Further study is required to understand the complexity of the impact values.

- microstructure studies of the welded joints revealed that due to auxiliary stirring of the weld pool during vibratory welding condition, steeper thermal gradients are established and more fine grain structures were obtained. 


\section{References}

1. S. Kou, Y. Le, Nucleation mechanism and grain refining of weld metal, Welding J. 65 (1986) 63-70

2. M.J. Jose, S.S. Kumar, A. Sharma, Vibration assisted welding processes and their influence on quality of welds, Sci. Technol. Weld. Join. 22 (2015) 243-258

3. Q. Lu, L. Chen, C. Ni, Improving welded valve quality by vibratory weld conditioning, Mater. Sci. Eng. A 457 (2007) 246253

4. L. Qinghua, C. Ligong, N. Chunzhen, Effect of vibratory weld conditioning on welded valve properties. Mech. Mater 40 (2008) 565-574

5. C.-C. Hsieh, C.-H. Lai, W. Wu, Effect of vibration on microstructure and mechanical properties of 304 Stainless steel GTA welds, Met. Mater. Int. 19 (2013) 835-844.

6. M. Malinowaski-Brodnicka, G. Den, W.J. Wink, Effect of magnetic fields on GTA welds in austenitic stainless steel, Weld. Res. Suppl. 52-s (1990) 52-59

7. C. Vives, Effect of electromagnetic vibration on the microstructure of continuously cast alloys, Mater. Sci. Eng. A 173 (1993) 169-172

8. $\mathrm{W}$. $\mathrm{Wu}$, Influence of vibration frequency on solidification of weldments, Scr. Matter 42 (2000) 661-665

9. A.S.M.Y. Munsi, A.J. Waddell, C.A. Walker, The effect of vibratory stress on the welding microstructure and residual stress distribution, J. Mater. Des. Appl. 215 (2001) 99-111

10. M. Sun, Y. Sun, R. Wang, Vibratory stress relieving of welded sheet steels of low alloy high strength steel, Mater. Lett. 58 (2004) 1396-1399

11. D. Rao, D. Wang, L. Chen, The effectiveness evaluation of 314L stainless steel vibratory stress relief by dynamic stress, Int. J. Fatig. 29 (2007) 192-196

12. X. Jijin, C. Ligong, N. Chunzhen, Effect of vibratory welds conditioning on residual stress and distortion in the multipass girth butt welded pipes, Int. J. Press. Vessel Pip. 84 (2007) 298-303

13. Y. Cui, C.L. X, Effect of ultrasonic vibration on unmixed zone formation. Scr. Mater 55 (2006) 957-958

14. B. Pucko, V. Gliha, Charpy toughness of vibrated microstructure. Original scientific paper-Izvorni Znanstveni Rad, Metalurgija 44 (2005) 103-106

15. Y. Lei, Z. Wang, X. Chen, Effect of ultrasound on microstructures and mechanical properties of plasma arc welded joints of $\mathrm{SiCp} / \mathrm{Al}$ MMCs, Trans. Nonferrous Metals Soc. China 21 (2011) 272-277

16. R. Dehmolaei, M. Shamanian, A. Kermanpur, Effect of electromagnetic vibration on the unmixed zone formation in $25 \mathrm{Cr}-35 \mathrm{Ni}$ heat resistant steel/Alloy 800 dissimilar welds, Mater. Charac. 59 (2008) 1814-1817

17. K. Balasubramanian, V. Balusamykeshavan, Studies on the effect of vibration on hot cracking and grain size in AA7075 Aluminum alloy welding, Int. J. Eng. Sci. Technol. 3 (2011) 1

18. P. Govind Rao, P. Srinivasa Rao, A. Gopala Krishna, Mechanical properties improvement of weldments using vibratory welding system. Inst. Mech. Eng. - J. Eng. Manuf. B 229 (2014) 776-784

19. A. Krajewski, W. Włosinski, T. Chmielewski, P. Kołodziejczak, Ultrasonic vibration assisted arc-welding of aluminum alloys. Bull. Polish Acad. Sci. Tech. Sci. 4 (2012) 841-852

20. J.S. Wang, C. Hsieh, C.M. Lin, E.C. Chen, C.W. Kuo, W. $\mathrm{Wu}$, The effect of residual stress relaxation of the vibratory stress relief technique on the textures of grains in AA 6061 Aluminum alloy, Mater. Sci. Eng. A 605 (2014) 98-107

21. A. Mostafapour, V. Gholizadeh, Experimental investigation of the effect of vibration on mechanical properties of 304 stainless steel welded parts, Int. J. Adv. Manuf. Technol. 70 (2014) 1113-1124

22. S. Amini, M. Amiri, Study of ultrasonic vibration's effect on friction stir welding, Int. J. Adv. Manufact. Technol. 73 (2014) 127-135

23. C. Hsieh, P. Wang, J. Wang, W. Wu, Evolution of Microstructure and residual stress under various vibration modes in 304 Stainless steel welds, Sci. World J. (2014) DOI: $10.1155 / 2014 / 895790$

24. T. Wen, S.Y. Liu, S. Che, L. Liu, C. Yang, Influence of high frequency vibration on microstructure and mechanical properties of TIG welding joints of AZ31 magnesium alloy, Trans. Nonferrous Metals Soc. China 25 (2015) 397-404

25. J. Wang, Q. Sun, L. Wu et al., Effect of ultrasonic vibration on microstructural evolution and mechanical properties of underwater wet welding joint, J. Mater. Process. Technol. 246 (2017) 185-197

26. Y. Ye, X. Li, J. Kuang, Y. Geng, G. Tang, Effects of electropulsing assisted ultrasonic impact treatment on welded components, Mater. Sci. Technol. 31 (2015) 1583-1588

27. M. Rahmi, M. Abbasi, Friction stir vibration welding process: modified version of friction stir welding process, Int. J. Adv. Manufact. Technol. (2016) DOI: 10.1007/s00170016-9383-9

28. S.P. Tiwari, A. Shanker, Effect of longitudinal vibration on mechanical properties of mild steel weldments. Proc. Inst Mech. Eng. B: J. Eng. Manuf. 207 (1993) 173-177

29. S. Kumar, C.S. Wu, G.K. Padhy, W. Ding, Application of ultrasonic vibrations in welding and metal processing: a status review, J. Manufact. Process. 26 (2017) 295-322

30. P.K. Singh, D. Patel, S.B. Prasad, Investigation on the effect of auxiliary vibrations on microstructure and mechanical properties of SMAW butt welded joints, Indian J. Eng. Mater. Sci. NISCAIR 25 (2018) 155-162

31. L. Shi, C. Wui, X. Liu, Modeling the effects of ultrasonic vibration on friction stir welding, J. Mater. Process. Technol. 36 (2015) 25-262

32. S. Rajakumar, C. Muralidharan, V. Balasubramanian, Optimization of the friction-stir-welding process and tool parameters to attain a maximum tensile strength of AA7075T6 aluminum alloy, Proc. Inst. Mech. Eng. Part B J. Eng. Manuf. 224 (2010) 1175-1191.

33. P. Bamankar, S. Sawant, Study of the effect of process parameters on depth of penetration and bead width in SAW process, Int. J. Adv. Eng. Res. Stud. 2 (2013) 8-10

34. Y.H.P. Manurung, M.A. Mohamed, A.Z. Abidin, Structural life enhancement on friction stir welded AA6061 with optimized process and HFMI/PIT parameters, Int. J. Adv. Manufact. Technol. (2016) DOI: 10.1007/s00170-016-9697-7

35. S. Kumar, A.S. Shahi, Effect of heat input on the microstructure and the mechanical properties of gas tungsten arc welded AISI 304 stainless steel joints, Mater. Des. 32 (2011) 3617-3623

36. S. Mahajan, N.S. Biradar, R. Raman, S. Mishra, Effect of mechanical arc oscillation on the grain structure of mild steel weld metal, Trans. Indian Inst. Metals 65 (2012) 171-177 
37. Rahul, H.K. Arya, R.K. Saxena, Effect of cooling rate on microstructure of SAW welded mild steel plate (grade C 25 as per IS 1570), Int. J. Mod. Eng. Res. 4 (2014) 222

38. P. Singh, D. Patel, S.B. Prasad, Investigation on the effect of vibrations on cooling behavior and mechanical properties of SMAW butt welded joints, Sci. Bull. Ser. D (2017) 79.

39. S. Fouladi, M. Abbasi, The effect of friction stir vibration welding process on characteristics of $\mathrm{SiO}_{2}$ incorporated joint, J. Mater. Process. Technol. 243 (2017) 23-30

40. F. Lefebvre, C. Peyrac, G. Elbel, HFMI: understanding the mechanisms for fatigue life improvement and repair of welded structures, Weld World (2017) DOI: 10.1007/s40194-017-0455-8

41. A.K. Pathak, G.L. Dutta, Three-dimensional finite element analysis to predict the different zones of microstructure in submerged arc welding, Proc. Inst. Mech. Eng. J. Eng. Manuf. B 218 (2003) 269-280

42. C. Shanjeevi, S. Satish Kumar, P. Sathiya, Multi-objective optimization of friction welding parameters in AISI 304L austenitic stainless steel and copper joints, Proc. Inst. Mech. Eng. J. Eng. Manuf. B 230 (2016) 449-457

43. P. Mondal, D. Bose, M. Tech, Optimization of the process parameters for mig welding of aisi 304 and is 1079 using fuzzy logic method, Int. Res. J. Eng. Technol. 2 (2015) 483-488

44. P.K. Singh, D. Patel, S.B. Prasad, Development of vibratory welding technique and tensile properties investigation of Shielded metal arc welded joints, Indian J. Sci. Technol. 9 (2016) DOI: 10.17485/ijst/2016/v9i35/92846

45. K.N.H. Yamamoto, S. Harada et al., Beneficial effects of low frequency pulsed MIG welding on grain refinement of weld metal and improvement of solidification cracking susceptibility of aluminum alloys, Weld. Int. 7 (1993) 456-461

46. X. Liang, Y. Wan, C. Zhang, B. Zhang, X. Meng, Comprehensive evaluation of welding quality for butt-welded by means of $\mathrm{CO}_{2}$ arc vibratory welding, Int. J. Adv. Manufact. Technol. 90 (2016) 1911-1920.

47. Y.B. Zhong, C.S. Wu, G.K. Padhy, Effect of ultrasonic vibration on welding load, temperature and material flow in friction stir welding, J. Mater. Process. Technol. 239 (2017) 273-283

48. P. Kumar Singh, S. Deepak Kumar, D. Patel, S.B. Prasad, Optimization of vibratory welding process parameters using response surface methodology, J. Mech. Sci. Technol. 31 (2017) 2487-2495

Cite this article as: Pravin Kumar Singh, Investigation on the effect of mechanical vibration in mild steel weld pool, Manufacturing Rev. 6, 21 (2019) 